\title{
Viviparity and habitat restrictions may influence the evolution of male reproductive genes in tsetse fly (Glossina) species
}

Grazia Savini $^{1 \dagger}$, Francesca Scolari ${ }^{1,2 \dagger}$, Lino Ometto ${ }^{1}$, Omar Rota-Stabelli, ${ }^{3,4}$, Davide Carraretto ${ }^{1}$, Ludvik M. Gomulski ${ }^{1}$, Giuliano Gasperi ${ }^{1}$, Adly M. M. Abd-Alla ${ }^{5 *}$, Serap Aksoy ${ }^{6}$, Geoffrey M. Attardo ${ }^{7}$ and Anna R. Malacrida ${ }^{1 *}$ (D)

\begin{abstract}
Background: Glossina species (tsetse flies), the sole vectors of African trypanosomes, maintained along their long evolutionary history a unique reproductive strategy, adenotrophic viviparity. Viviparity reduces their reproductive rate and, as such, imposes strong selective pressures on males for reproductive success. These species live in subSaharan Africa, where the distributions of the main sub-genera Fusca, Morsitans, and Palpalis are restricted to forest, savannah, and riverine habitats, respectively. Here we aim at identifying the evolutionary patterns of the male reproductive genes of six species belonging to these three main sub-genera. We then interpreted the different patterns we found across the species in the light of viviparity and the specific habitat restrictions, which are known to shape reproductive behavior.

Results: We used a comparative genomic approach to build consensus evolutionary trees that portray the selective pressure acting on the male reproductive genes in these lineages. Such trees reflect the long and divergent demographic history that led to an allopatric distribution of the Fusca, Morsitans, and Palpalis species groups. A dataset of over 1700 male reproductive genes remained conserved over the long evolutionary time scale (estimated at 26.7 million years) across the genomes of the six species. We suggest that this conservation may result from strong functional selective pressure on the male imposed by viviparity. It is noteworthy that more than half of these conserved genes are novel sequences that are unique to the Glossina genus and are candidates for selection in the different lineages.
\end{abstract}

\footnotetext{
* Correspondence: A.M.M.Abd-Alla@iaea.org; malacrid@unipv.it

${ }^{\dagger}$ Grazia Savini and Francesca Scolari contributed equally to this work.

${ }^{5}$ Insect Pest Control Laboratory, Joint FAO/IAEA Programme of Nuclear

Techniques in Food \& Agriculture, Vienna, Vienna, Austria

'Department of Biology and Biotechnology, University of Pavia, Pavia, Italy

Full list of author information is available at the end of the article
}

(C) The Author(s). 2021 Open Access This article is licensed under a Creative Commons Attribution 4.0 International License, which permits use, sharing, adaptation, distribution and reproduction in any medium or format, as long as you give appropriate credit to the original author(s) and the source, provide a link to the Creative Commons licence, and indicate if changes were made. The images or other third party material in this article are included in the article's Creative Commons licence, unless indicated otherwise in a credit line to the material. If material is not included in the article's Creative Commons licence and your intended use is not permitted by statutory regulation or exceeds the permitted use, you will need to obtain permission directly from the copyright holder. To view a copy of this licence, visit http://creativecommons.org/licenses/by/4.0/ The Creative Commons Public Domain Dedication waiver (http://creativecommons.org/publicdomain/zero/1.0/) applies to the data made available in this article, unless otherwise stated in a credit line to the data. 
Conclusions: Tsetse flies represent a model to interpret the evolution and differentiation of male reproductive biology under different, but complementary, perspectives. In the light of viviparity, we must take into account that these genes are constrained by a post-fertilization arena for genomic conflicts created by viviparity and absent in ovipositing species. This constraint implies a continuous antagonistic co-evolution between the parental genomes, thus accelerating inter-population post-zygotic isolation and, ultimately, favoring speciation. Ecological restrictions that affect reproductive behavior may further shape such antagonistic co-evolution.

Keywords: Glossina, Male accessory gland genes, Testis genes, Habitat, Viviparity, Selective pressure

\section{Background}

The ability to secure mates and achieve fertilization is a fundamental measure of male reproductive success [1], and at the core of this is the ejaculate, which is responsible for inducing important post-mating responses in females $[2,3]$. Traits and male reproductive genes involved in these post-copulatory interactions have been suggested to evolve rapidly due to sexual selection and sexual conflict [4-19]. This rapid evolution potentially leads to reproductive incompatibilities among lineages due to disruptions in male reproductive hybrid fitness [20-23]. Accelerated evolution in male reproductive genes is expected in viviparous insects, which invest considerable energy to produce a limited number of highquality progeny. Indeed, viviparous reproduction reduces the reproductive capacity/rate, leading to increased inter- and intra-sexual conflict. This is the case of Glossina flies, sole members of the Glossinidae family (Schizophora, Calyptratae) and typical examples of K-strategists [24]. These flies reproduce through adenotrophic viviparity, which is defined as having intrauterine larval development and provision of all larval nourishment by the milk glands for the duration of its development [24-26]. This mode of reproduction has been associated with extreme morphological and functional adaptations [24, 27]. In these flies, a very important adaptive trait for fertilization is that the male ejaculate is encapsulated into a spermatophore, which is assembled within the female uterus from the secretions of the male accessory glands (MAGs) and testes during the later stages of copulation $[28,29]$. The spermatophore functions as a protective container for the ejaculate, ensuring semen/sperm delivery directly to the female spermathecal ducts and inhibition of insemination by competing males [27, 29].

From an ecological point of view, tsetse flies are restricted to and distributed throughout sub-Saharan Africa, where they are the vectors of African trypanosomiasis in humans and animals [30-32]. Based on a combination of geographical distribution, behavioral, molecular, and morphological features, Glossina can be generally divided into three sub-genus groups of species: (i) Morsitans, largely savannah and woodland flies; (ii) Palpalis, riverine and lacustrine inhabitants, and (iii) Fusca, which are forest flies of West Africa [33]. The habitat restriction of each species group is an important and immediate determinant of their behavior [34]. It is conceivable that such habitat/ecoclimate restrictions could affect, at the population level, the number of interactions of males and females before, during and post-mating, thus impacting the intensity of intraand intersexual conflict [35]. Indeed, different remating rates have been observed among members of the Morsitans and Palpalis groups [36-38].

It is still unknown whether the different levels of intraand intersexual selective pressure potentially associated with habitat restrictions are reflected in Glossina lineage-specific patterns of evolution and positive selection of male reproductive genes. Here, we aim at exploring whether species with different habitat restrictions display different patterns of male reproductive gene evolution. To do so, we made use of the genome sequences of six species belonging to the Fusca (i.e., Glossina brevipalpis), Morsitans (i.e., G. m. morsitans, G. pallidipes, G. austeni), and Palpalis (i.e., G. fuscipes, G. palpalis) groups [30, 39], and the functional data obtained from the spermatophore proteome and the transcriptomes derived from the two male reproductive compartments, testes and MAGs, from G. m. morsitans [29].

We first derived a time-calibrated phylogeny of the six Glossina species to reconstruct their long evolutionary history. Next, we tested for evidence of positive selection in the male reproductive genes from the testes and MAGs. The data indicate that the overall evolutionary patterns of reproductive genes are consistent with the evolutionary history and the biology of the different Glossina lineages. Moreover, the evolutionary rate of genes from MAGs is faster than that of testes and is heterogeneous among and within the species groups.

\section{Results}

Time-calibrated phylogeny of Glossina species from the Morsitans, Palpalis, and Fusca groups

As a premise to the analysis of the evolution of male reproductive genes in Glossina, a time-calibrated phylogeny of species within the Morsitans, Palpalis, and Fusca groups was obtained using Musca domestica (Calyptratae), three Drosophila species (Acalyptratae), Lutzomyia longipalpis, and Anopheles gambiae as outgroups (Fig. 1). This time-calibrated phylogeny, based on 


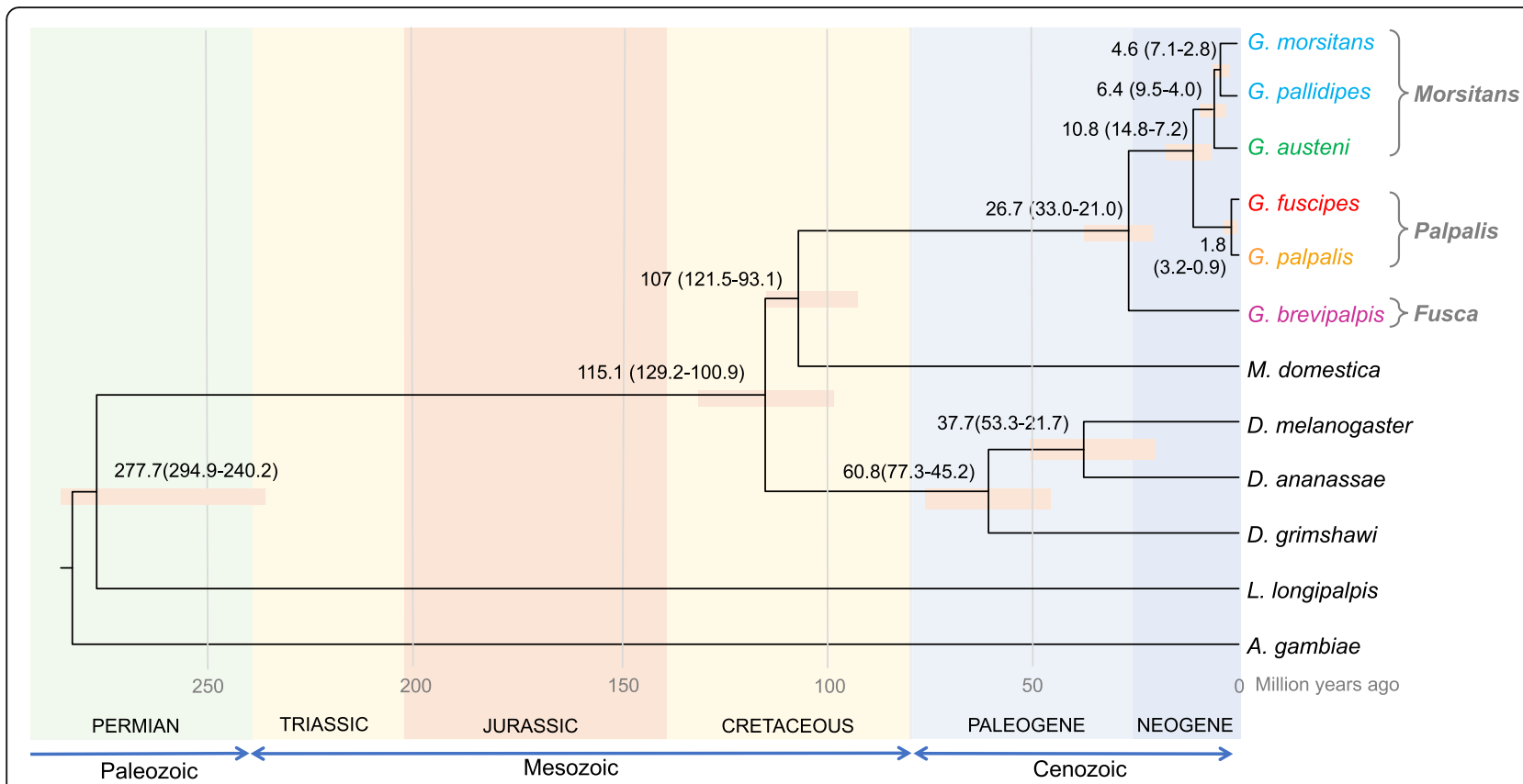

Fig. 1 Genome-scaled phylogeny and divergence estimates. Bayesian consensus tree inferred on a dataset of 478,000 nucleotides by PhyloBayes using relaxed clocks and node/fossil constraints. Numbers at nodes are main divergence estimates and 95\% High Posterior Densities, HPD (in parentheses) expressed in millions of years. Bars are the 95\% HPD. All nodes received full support (100 Bootstrap support and 1.00 posterior probabilities, PP) in a Maximum Likelihood (RAxML) and Bayesian (PhyloBayes) analysis, except for the split of M. domestica from Glossina which had a PP of 0.96

the previously developed genome-scaled data [30], suggests a mid-Cretaceous origin of the lineage leading to the Glossina genus (stem-group Glossina, mean of 107 million years ago (mya), posterior densities in Fig. 1) with an Oligocene radiation of extant Glossina species. Glossina brevipalpis diverged from the forest Fusca group at a mean of 26.7 mya. The divergence of the savannah Morsitans from the riverine Palpalis groups dated toward the middle Neogene (mean 10.8 mya). Within the Morsitans group, G. m. morsitans, G. pallidipes, and G. austeni diverged toward the end of the Neogene (mean 4.6 mya), while G. austeni split from the Morsitans group at 6.4 mya. The split of G. fuscipes from G. palpalis within the Palpalis group was the most recent with a mean of 1.8 mya. Based on these timecalibrated relationships, phylogeny-based tests of positive selection on male reproductive genes from testes and MAG body compartments were performed.

\section{Across the Glossina lineages the male reproductive genes from MAGs and testes are under different selective pressure}

A total of 5513 orthologous sequences (out of the 8088 considered) were detected across the six Glossina genomes (Table S1, S2). These orthologs were overlapped with a G. m. morsitans dataset of 2563 genes, of which 2436 display enriched transcription ( $\geq 5$-fold) in the testes (TSTGs) and 127 in the MAGs (MAGGs) [29]. The overlapping orthologs consisted of 1924 TSTGs and 92 MAGGs and their species distribution is reported in Fig. 2. Due to its basal phylogenetic position, G. brevipalpis from the Fusca group shares the fewest orthologs (85\% for TSTGs, 69\% for MAGGs), probably due to high sequence divergence hindering a proper orthology assignation. It cannot be excluded, however, that this difference in the number of orthologs is also the result of a gain of TSTGs and MAGGs in the clade containing the other five species.

The nonsynonymous $\left(d_{\mathrm{N}}\right)$ and synonymous $\left(d_{\mathrm{S}}\right)$ substitution estimates on the MAGG and TSTG orthologs (92 and 1924, respectively), as well as for the all 5513 orthologs, indicate that the average level of selective pressure, measured by $d_{\mathrm{N}} / d_{\mathrm{S}}$, was significantly higher in MAGGs $(0.183 \pm 0.178 \mathrm{SD}$, var $=0.032)$ than in TSTGs $(0.085 \pm 0.068 \mathrm{SD}$, var $=0.005)$ and "all genes" combined $(0.088 \pm 0.071 \mathrm{SD}$, var $=0.005)$, which are used as a proxy of the genome-wide level (Wilcoxon test $P<10^{-5}$, for both comparisons). Moreover, there is a high heterogeneity in the selective pressure across MAGGs when compared to either TSTGs and "all genes" (Bartlett test of homogeneity of variances, K-squared $=196.97, \mathrm{df}=1$, $P<10^{-15}$; and $K$-squared $=187.44, \mathrm{df}=1, P<10^{-15}$, respectively), which is expected in presence of contrasting selective regimes (i.e., positive, purifying, and relaxed). In 


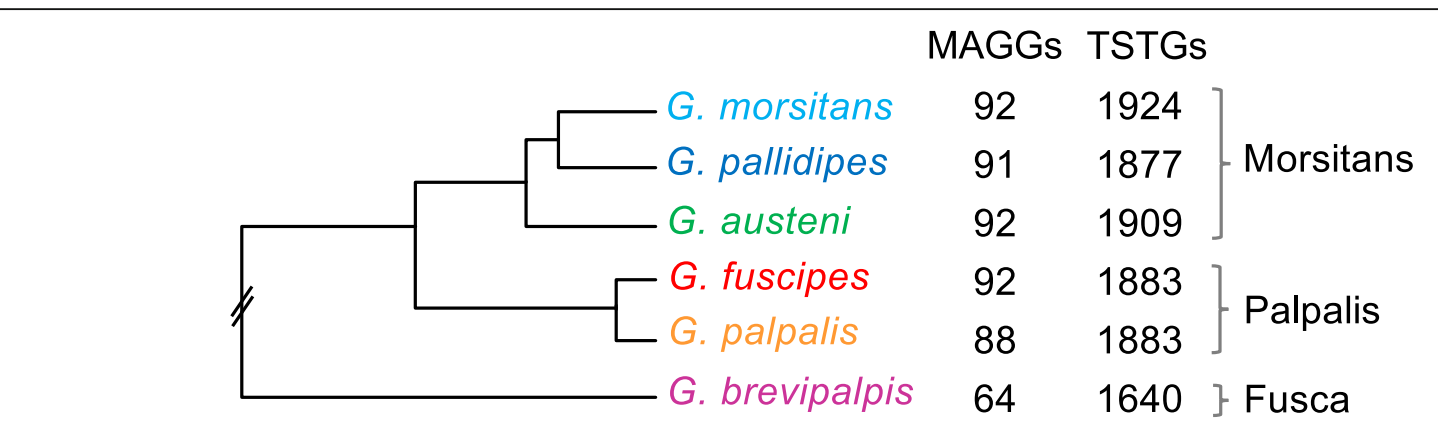

Fig. 2 Evolution of TSTGs and MAGGs orthologs on the Glossina phylogeny. Number of genes orthologous to G. m. morsitans TSTGs and MAGGs for all considered Glossina species

contrast, TSTGs were under a rate of molecular evolution similar, if not even more constrained, to the trend detected across the genome (Wilcoxon test $P=0.215$; and Bartlett test of homogeneity of variances, $K$-squared $=6.721, \mathrm{df}=1, P=0.010$; Table S2).

The heterogeneity in the selective pressure on MAGGs with respect to TSTGs is also reflected at the level of gene functional categories. Indeed, the 17 Gene Ontology (GO) categories of MAGGs display a $d_{\mathrm{N}} / d_{\mathrm{S}}$ average estimate of 0.2 , ranging from a maximum estimate of 0.42 for "odorant binding" to a minimum value of 0.03 for "carbohydrate derivative binding" (Fig. 3; Table S1, S3). Heterogeneity for $d_{\mathrm{N}} / d_{\mathrm{S}}$ is also present within classes: odorant-binding proteins (OBPs) include six genes with $d_{\mathrm{N}} / d_{\mathrm{S}}$ from 0.12 (GMOY005875) to 0.73 (GMOY007314), and the novel tsetse protein (NTP) gene category [29], with estimates from < 0.1 (GMOY002769) to 1.22 (GMOY007759). The NTP category comprises genes that share no similarity to annotated sequences deposited in the GenBank database, as well as no recognizable domains based on BLAST analyses and structural homology searches (e.g., [40-43]. Conversely, the $42 \mathrm{GO}$ functional categories of TSTGs

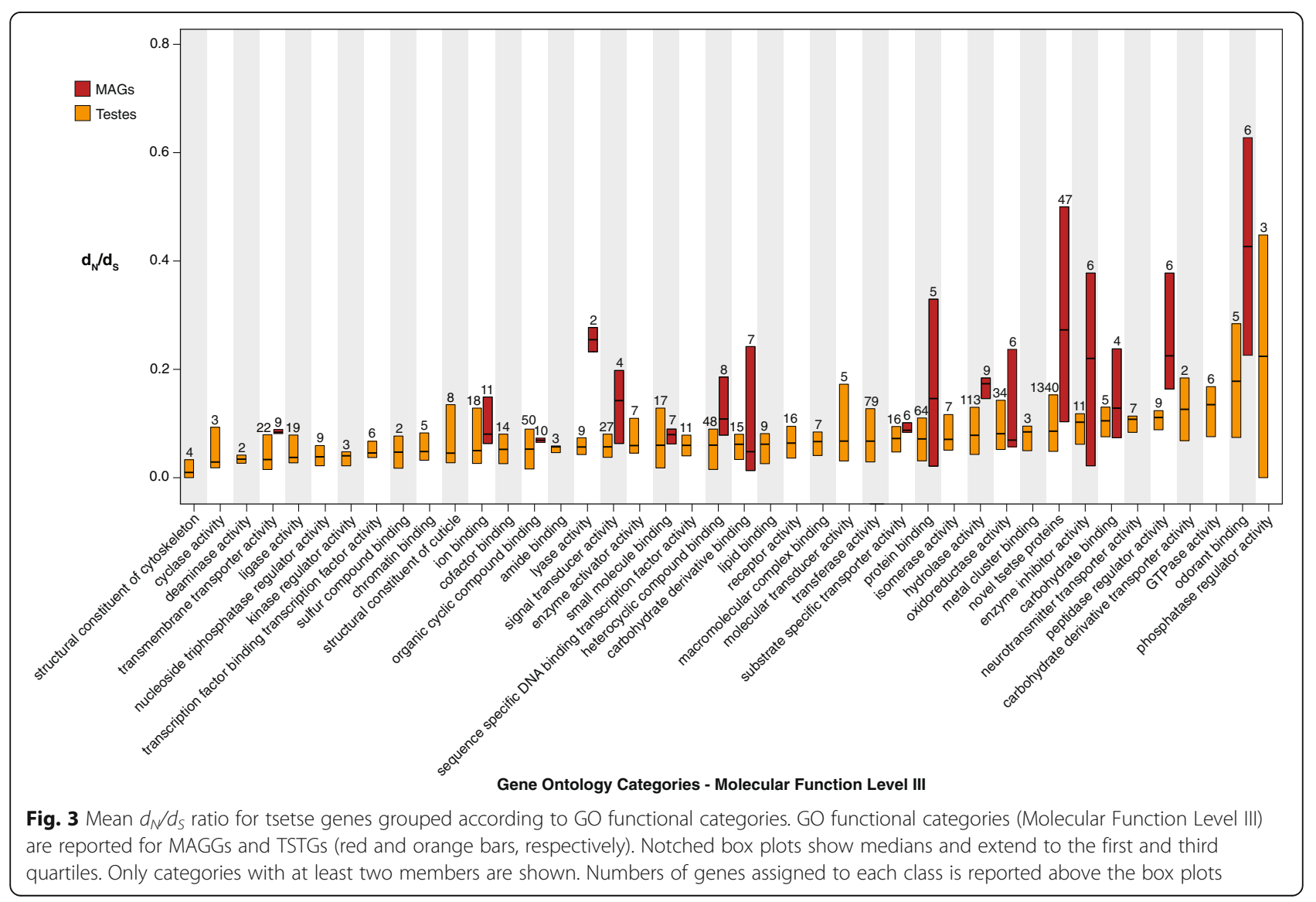


displayed low heterogeneity and very low values in the $d_{\mathrm{N}} /$ $d_{\mathrm{S}}$ average estimates (mean $d_{\mathrm{N}} / d_{\mathrm{S}}=0.1$ ), indicative of strong purifying selection. The most heterogeneous classes are OBPs and phosphatase regulators.

\section{The MAG and testes genes evolve differentially in the Morsitans, Palpalis, and Fusca lineages}

Consensus evolutionary trees were generated both for $d_{\mathrm{N}}$ and $d_{\mathrm{S}}$ substitutions in MAGGs, TSTGs and "all genes" based on the unrooted tree estimated in our previous phylogenetic analysis [30]. The rates of $d_{\mathrm{N}}$ and $d_{\mathrm{S}}$ were estimated over all branches. MAGGs showed significantly higher $d_{\mathrm{N}}$ relative to TSTGs and to "all genes," in all the six Glossina lineages analyzed (Tukey HSD test, $P<0.05$ ) (Fig. 4; Table S2). But the level of selective pressure on MAGGs is heterogeneous both within and among the species groups. Within the savannah Morsitans group, the G. austeni lineage displays the highest $d_{\mathrm{N}} / d_{\mathrm{S}}$ value (0.293), while in the riverine Palpalis group, G. fuscipes shows the highest estimate $\left(d_{\mathrm{N}} / d_{\mathrm{S}}=0.307\right)$.

For TSTGs, the level of selective pressure in the riverine Palpalis group appears to be higher with respect to the Morsitans species (Fig. 4). It is noteworthy that the differences in selective pressure on TSTGs among the species are maintained also at the level of "all genes" category (Fig. 4).

\section{Candidates for selection in Glossina lineages include genes encoding ejaculate proteins}

Different models of substitution rates across coding sites (i.e., site, branch, and branch-site tests) allowed the identification of 750 genes as candidates for selection in at least one test in at least one branch of the phylogeny of the Morsitans and Palpalis groups (i.e., G. m. morsitans, G. pallidipes, G. austeni; G. palpalis, G. fuscipes) using a false discovery rate of $20 \%$ as a threshold. Among these, 176 were from testes and 10 from MAGs (Table S4, S5). Globally, when the pattern of evolution of the MAGGs and TSTGs is evaluated in relation to the divergence time of the species, it appears that the selection rate is higher in the Palpalis than in the Morsitans group, with the exception of G. austeni (Fig. 5).

The testes and MAG candidates for selection are differently distributed among the species (Fig. 6; Tables S4, S5). These genes include sequences which, in G. m. morsitans, encode for ejaculate proteins (i.e., 15 from testes and 7 from MAGs), and many novel tsetse protein (NTP) genes (i.e., 83 from testes and 4 from MAGs).

As far as it concerns testes genes, the Morsitans species group globally displays a higher number of candidates for selection than Palpalis (106 vs 36) (Fig. 6; Table S4). Indeed, G. austeni has 53 candidates, with $43 \%$ of them $(n=23)$ being NTPs. Four of these genes

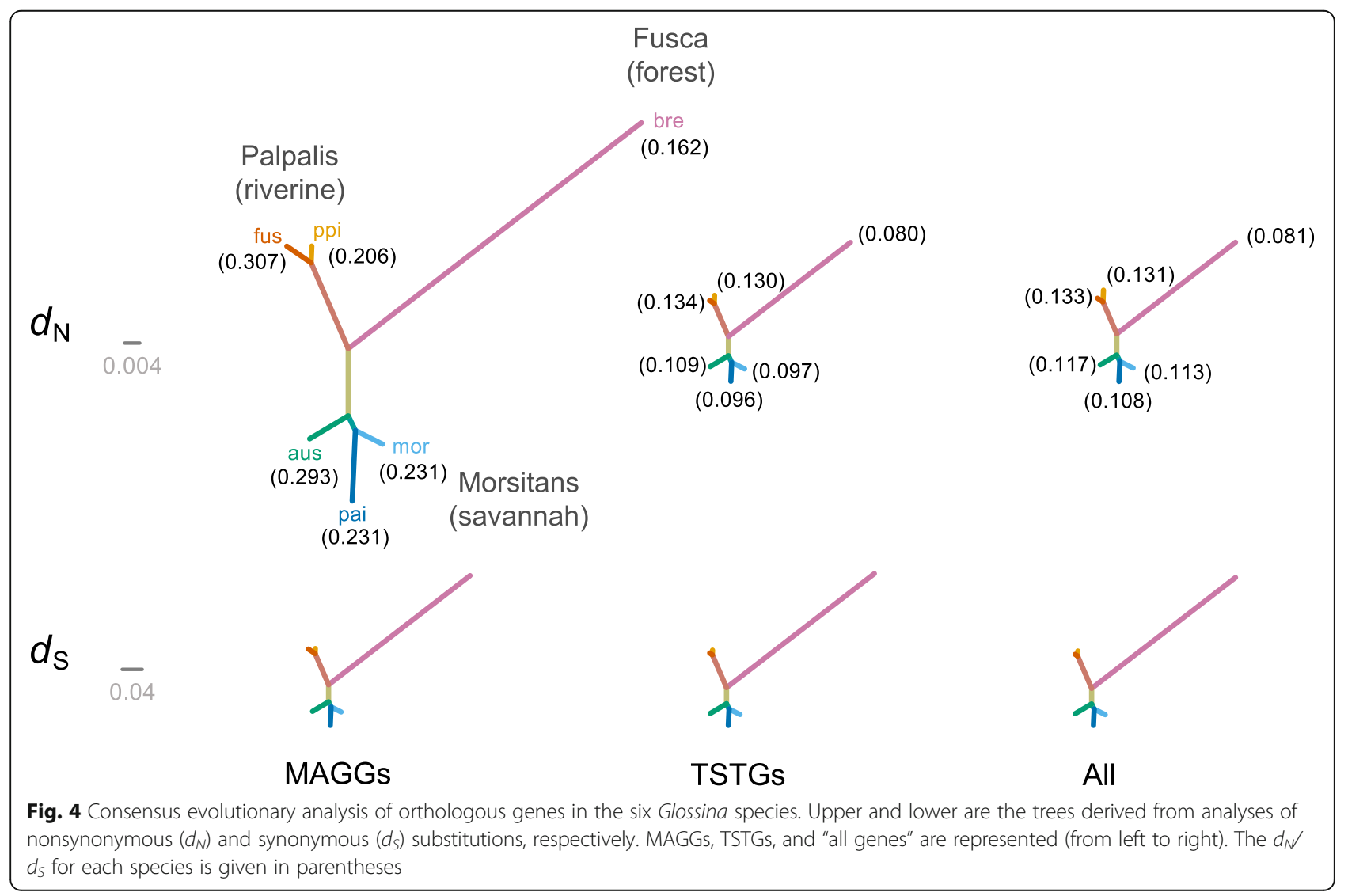




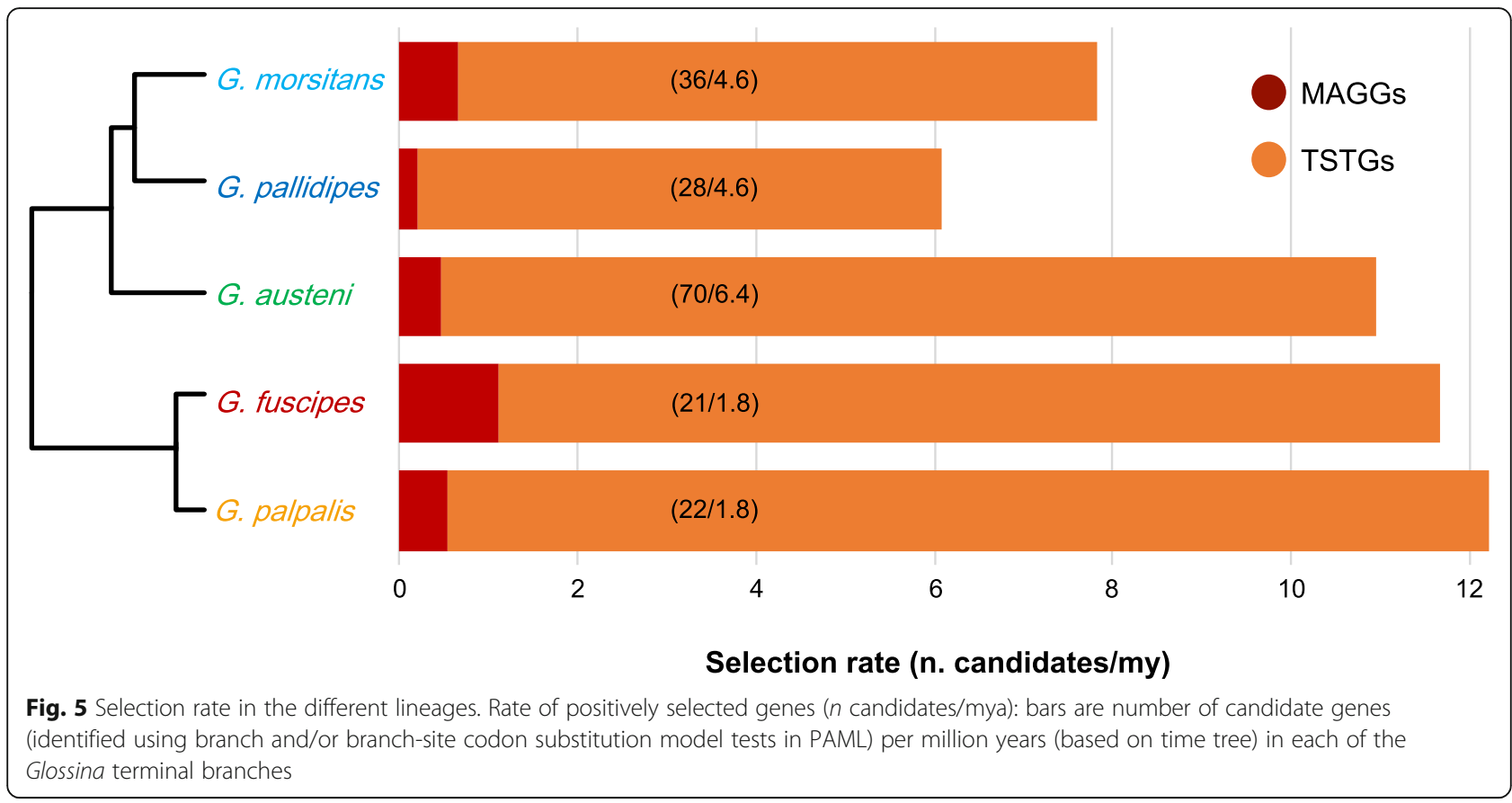

encode for predicted ejaculate proteins: Laminin $A$ (GMOY006100), blue cheese (GMOY010447), and two NTP genes (GMOY009072 and GMOY009618). In G. $m$. morsitans, out of the 22 candidates, $40 \%(n=9)$ are NTP genes and include the ejaculate protein gene Malic enzyme (GMOY007044) (Fig. 6; Table S4). In the more recently evolved Palpalis group, G. palpalis has 16 candidates for selection, with 37\% being NTP genes, and including three predicted ejaculate protein genes: two NTP genes (GMOY002349, GMOY008094) and the extracellular matrix proteoglycan-like sulfate glycoprotein Papilin (GMOY007883) [44]. In G. fuscipes, among the 14 candidates, $64 \%(n=9)$ are NTP genes (Fig. 6; Table S4).

As far as it concerns the MAG candidates for selection, the three genes in G. m. morsitans encode for ejaculate proteins [29], i.e., deoxyribonuclease-2-alpha (GMOY002550), a putative OBP (GMOY005874), and the NTP gene GMOY004505 (Fig. 6; Table S5). In G. austeni and in G. pallidipes, only one candidate was identified: the ejaculate protein-coding gene ance (GMOY009723), and one NTP gene (GMOY002583), respectively. In the Palpalis species group, only one candidate for selection was identified, the transmembrane channel 1 (GMOY005914) in G. fuscipes.

\section{Discussion}

Using a comparative genomic approach, we identified and screened for signals of selection in the male reproductive genes of six Glossina species representative of the Fusca, Morsitans, and Palpalis sub-genera. The data indicate that the overall evolutionary patterns of male reproductive genes are consistent with the timecalibrated phylogeny of these Glossina groups. However, the evolutionary rate of genes from the MAGs is faster than that of testes-specific/enriched genes and is heterogeneous among and within the species groups. Genes encoding ejaculate proteins and novel tsetse proteins (NTPs) have been found to be under selective pressure.

\section{Glossina male reproductive genes' evolution and viviparity}

A large dataset of male reproductive genes remained conserved over the long evolutionary time scale (estimated at 26.7 mya) across the genome of the six Glossina species from Fusca, Morsitans, and Palpalis subgenera (from 1704 genes in G. brevipalpis / Fusca group, to 2016 genes in G. m. morsitans / Morsitans group). This male reproductive gene conservation may be interpreted as the consequence of the strong functional selective pressure on the male imposed by the viviparous reproductive condition (see [45] for a review). It is noteworthy that more than half of these conserved sequences are NTP genes that are unique to the Glossina genus and are candidates for selection in the different lineages $[12,46]$.

Given that viviparity in Glossina leads to the production of only a few progeny [24], the conflict between competing individual males to increase their success for fertilization is exacerbated with respect to oviparous species $[45,47]$. But also the female exerts pressure on the male through post-mating sexual selection by biasing male fertilization success through cryptic female choice 


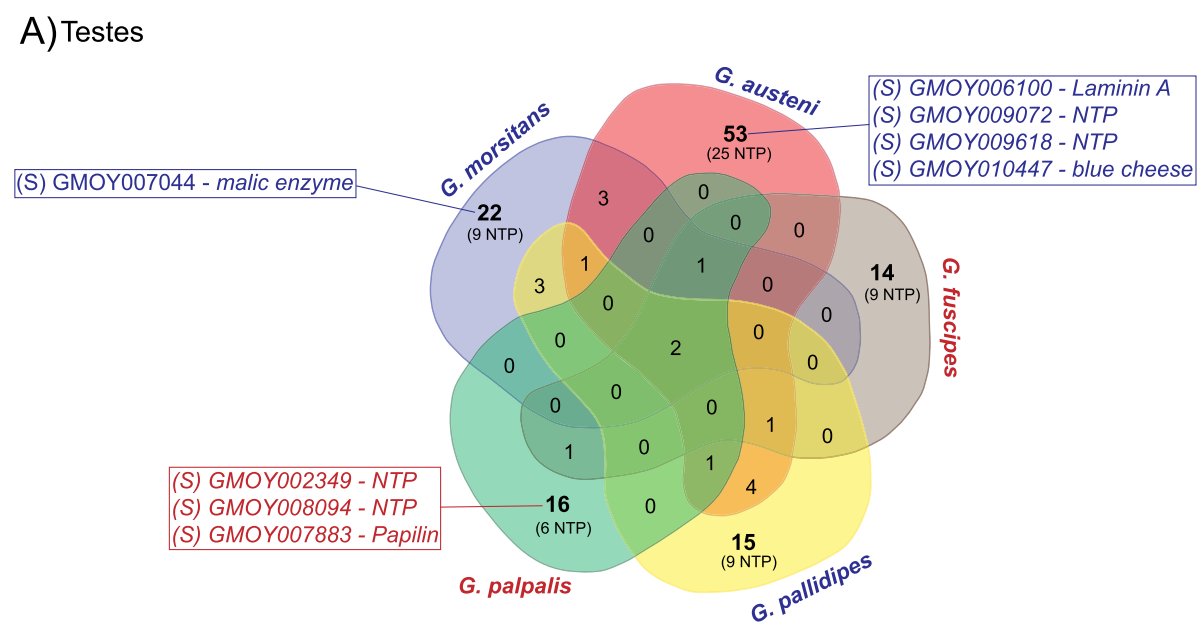

B)MAGs

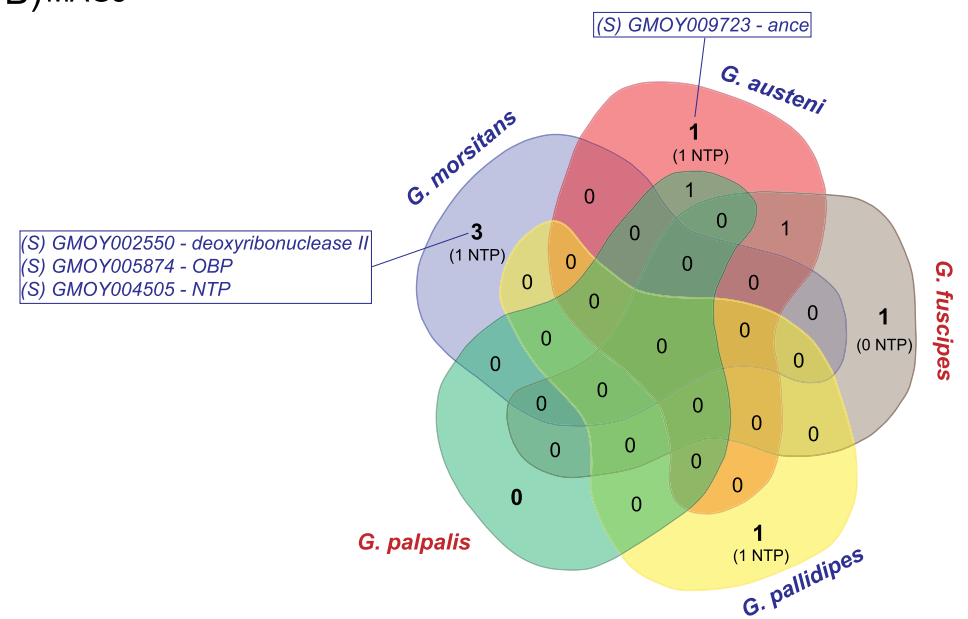

Fig. 6 Reproductive genes under selective pressure in the Glossina lineages. Numbers of unique and shared candidates for TSTGs (A) and MAGGs (B) are reported. Among these groups, genes found to encode spermatophore proteins in G. m. morsitans (29) are indicated in boxes and labelled with an (S). In brackets, the novel tsetse protein-coding genes (NTP) are indicated. Species belonging to the Morsitans and Palpalis species group are indicated in blue and red, respectively

and sperm competition [36, 48, 49]. An additional role in these post-mating conflicts is played by the male ejaculate transferred to the female and the female receptivity [50-52]. As in most animals, the ejaculate of G. $m$. morsitans is derived from the male reproductive organs, testes and MAGs, with each tissue making specific and distinct contributions to the ejaculate composition. The testes express genes primarily associated with spermatogenesis (and its regulation), sperm storage, transfer, and fertilization functions. Male accessory glands express a smaller set of genes at a high level that encode for the abundant non-sperm associated components of the ejaculate [29]. It is noteworthy that $72 \%$ of the testes and MAG sequences are conserved across the species analyzed. These genes probably serve different functions and are under different and contrasting intensities of selective pressure. Indeed, TSTGs display, across all functional GO categories, an average $d_{\mathrm{N}} / d_{\mathrm{S}}$ estimate of 0.1 , suggesting the action of strong and pervasive purifying selection. By contrast, MAGGs, though less numerous, display an average $d_{\mathrm{N}} / d_{\mathrm{S}}$ estimate of 0.2 , but they are heterogeneous for evolutionary rates. This finding indicates the presence of a combination of purifying, positive, and relaxed selection across the GO categories, in agreement with their different functional roles in post-mating female responses and male reproductive success as found in other insects [53, 54] and suggested for G. m. morsitans [29]. Novel tsetse genes, genes with predicted odorant binding, enzyme inhibitor, and protein binding functions are the categories that are under higher selective pressure in the MAGs with respect to the testes. These gene classes code for the most abundant proteins in the G. m. morsitans ejaculate [29]. The presence of OBP genes that are under selective pressure 
in the MAGs that code for proteins transferred to the female in the ejaculate raises the interest in their function in Glossina reproductive biology. Recent data from Drosophila, mosquitoes, and fruit flies suggest that OBPs may be involved in bringing odorants or pheromones next to the odorant receptors present in the female reproductive tracts or carry male-specific molecules into female tissues to elicit behavioral responses [55-62]. Whether tsetse OBP genes expressed in the male reproductive tract have similar functions and influence fertility and fecundity are open questions.

We previously explored the level of conservation of Glossina male reproductive genes in oviparous insects such as Musca domestica, Drosophila melanogaster, Aedes spp., and Anopheles gambiae that also display different strategies for ejaculate delivery and assembly [29]. Apart from the NTP genes, which are specific to Glossina, the conservation of tsetse male reproductive genes followed the expected phylogenetic relationships among the considered taxa, with sperm-related genes being more conserved than seminal fluid genes [29]. This trend is particularly evident when comparing G. m. morsitans with An. gambiae, as seminal fluid components of the mosquito mating plug did not display any similarity to those of the tsetse spermatophore. Considering the evolutionary rates of male reproductive genes in other insects, the conserved MAG genes within the An. gambiae sensu lato species complex that include those encoding plug components, are subjected to a relaxation of purifying selection [7], as we observed in Glossina.

The evolution of male reproductive genes in the different Glossina lineages may be affected by habitat restrictions and behavior

The consensus evolutionary trees, generated across the lineages both for the $d_{\mathrm{N}}$ and $d_{\mathrm{S}}$ substitutions in MAGGs, TSTGs, and "all genes" (Fig. 4), reflect the long and divergent demographic history of the Fusca, Morsitans, and Palpalis groups. Indeed species from these subgenera display an allopatric distribution, testifying their long separation during which random drift, fluctuating climates, and different selective regimes have promoted divergence and defined restricted habitat specificity for each group and species [30]. Fusca, a sister group to other tsetse lineages [63], contains species, such as G. brevipalpis, that occupy the ancestral forest habitat [64], and it was the first lineage to differentiate at 26.7 mya. This finding is consistent with the Oligocene Glossina fossil records found in Colorado (USA), which are dated from 33.9 to 23 mya $[65,66]$. The Morsitans group diverged from Fusca at a mean of 10.8 mya, with most posterior estimates between 14.8 and 7.2 mya. These estimates are compatible with a Morsitans adaptation to the savannah habitat that appeared in sub-Saharan
Africa about 7-8 mya (Miocene to Pliocene boundary) $[67,68]$. Similarly, the split of the Palpalis group from Morsitans may have been an adaptation to riverine habitats that occurred at about 10.8 mya. The riverine group currently inhabits the vegetation close to water sources [69]. The habitat restrictions for these species had an important effect on their behavior, leading to specializations in inter- and intra-sexual interactions, to ensure efficient insemination $[70,71]$. In this context, the male reproductive genes likely played a key role.

We found that the level of selective pressure on male reproductive genes, especially in the MAGs, is higher in the Palpalis/riverine species than in the Morsitans/ savannah group. This trend is particularly evident in $G$. fuscipes. Palpalis species, living in narrow riverine habitats, suffer seasonal demographic fluctuations. During the dry season, populations undergo demographic contractions with the remaining flies concentrating in moist refugia. At the end of the dry season, within the residual population emerging after the bottleneck, the strength of male competition increases because of the greater number of interactions for achieving copulation. In these expanding populations, higher remating rates have been observed than in the population contractions typical of the dry season [36]. Such remating rates are not unexpected given that cryptic female choice and multiple mating may provide a buffer against changing ecoclimates [72].

By contrast, Morsitans species occupy a more stable environment [34]. They inhabit extensive, relatively homogeneous, and open woodlands, and their populations are strongly allopatric with restricted gene flow and a relatively high dispersal capacity. Remating rate is lower [73], suggesting the presence of a less intense sexual selective pressure. Among these species, G. austeni is an exception both in terms of habitat restriction and of candidate male reproductive genes under selection. Indeed, this species is confined to a narrow discontinuous belt on the East African coast and it does not move far from its breeding habitats [74]. Remating rates in this species are high $[73,75,76]$. By contrast with the other members of the Morsitans group, the males display a very precocious MAG and spermatogenesis machinery development that permits the production of the ejaculate for an efficient insemination within the first $24 \mathrm{~h}$ after eclosion $[75,76]$. This behavior may support the high selective pressure we found on MAGGs and the higher number of testes candidate genes for selection with respect to the other species.

\section{Conclusions}

Here we attempted to interpret the evolution of male reproductive genes in Glossina species considering their peculiar adaptations, such as obligate viviparity and strict 
habitat specificity. With respect to viviparity, the observed signatures of gene evolution may be considered in the light of the very tight co-evolution between male and female genomes. Indeed, viviparity creates a post-fertilization arena for genomic conflicts that are absent in ovipositing species [45, 47, 77-80]. These conflicts can arise between the mother and the developing embryo in the uterus, but also between the maternal and paternal genomes within the embryo (see [45] for a review). As a consequence, a continuous antagonistic co-evolution occurs between the parental genomes, thus accelerating inter-population postzygotic isolation and, ultimately, speciation. Ecological restrictions that affect reproductive behavior of these species may further shape such antagonistic coevolution. Glossina flies offer an ideal opportunity to investigate these patterns and the underlying regulatory mechanisms. These aspects are of great interest considering the important role these flies play as vectors of parasitic trypanosomes in Africa. In the absence of vaccines, the best available method to limit the burden of disease is to control Glossina as vectors. Unfortunately, most vector control strategies rely on the use of insecticides. Given the strong limitations imposed by viviparity on reproductive output, development of effective strategies to interfere with Glossina reproduction in the field is a desirable approach. Our list of conserved NTP genes is a valuable starting point for the selection and testing of new targets for the identification of mechanisms regulating fertility in these species. This is a necessary step towards the development of translational applications.

\section{Methods}

\section{Time-calibrated phylogeny}

Data from G. m. morsitans genome were used to conduct a comprehensive multi-locus dated phylogenetic analysis in the context of the available genome data from Glossina species, i.e., G. pallidipes, G. austeni, G. fuscipes, G. palpalis, and G. brevipalpis [30, 39]. To maximize the power of our phylogenetic analysis, several outgroup species were incorporated into the study. These include Musca domestica as a representative of the Calyptrates, Drosophila melanogaster, D. ananassae, and D. grimshawi representing the Acalyptrates, and Lutzomyia longipalpis and Anopheles gambiae representing the Nematocera. The strains and the genome resources are given in Table S6.

Orthologous genes across the six Glossina and the outgroup species were identified following the same procedure as described by Attardo and colleagues [30] using G. m. morsitans as focal species, aligning individually using MAFFT [81] and concatenating in a super-alignment of 478,617 nucleotide positions. We inferred divergence estimates using PhyloBayes (4.1; https://megasun.bch.umontreal.ca/People/lartillot/ www/download.html) [82] on the gblocked amino acid dataset. Divergence rates were calibrated at four nodes: (a) a minimum of 33 million years (my) for the divergence of the Glossina genus based on the oldest Glossina fossil from the Florrisant Beds estimated to be late Eocene [83]; (b) a maximum of 294.5 and a minimum of 238.5 my for the Drosophila/Anopheles split [84]; (c) a minimum of $64 \mathrm{my}$ for the Glossina/D. melanogaster split; (d) a minimum of 44 my for the Drosophila genus divergence [85]. All node constraints were treated as soft allowing $5 \%$ of mass allocation outside both boundaries [86]. A LogNormal relaxed molecular clock, a GTR + G replacement model, and a Birth and Death tree prior were used. Two independent chains were run until consensus trees converged on extremely similar divergence estimates. Final divergences were calculated on one of the chains after exclusion of the first $10 \%$ of sampled trees as burn-in.

\section{Estimates of divergence and test for positive selection of male reproductive genes \\ Orthologous gene set identification}

The coding sequences of all six species were obtained from VectorBase (www.vectorbase.org), and then used in pairwise BLASTn between the G. m. morsitans sequences and those of the other Glossina species. To identify orthologs, we used a reciprocal-best-BLASThits (RBH) approach [87] in which G. m. morsitans was used as focal species. We retrieved a total of 8088 orthologous groups represented by at least five Glossina species (G. morsitans being always one of the five), 5513 of which had all six orthologous sequences. We then partitioned our dataset based on a stringently selected set of genes which, in G. m. morsitans, displayed enriched transcription in male accessory glands (MAGGs) or testes (TSTGs), respectively ( $\geq 5$-fold) [29].

\section{Analyses of the rate of evolution of male reproductive genes in Glossina species}

All orthologous sequences were aligned using PRANK (version 14.06.03) in codon mode [88], as implemented in TranslatorX [89], which aligns proteincoding nucleotide sequences based on their corresponding amino acid translations. To minimize the possibility of spurious matches, orthologous sets with sequences shorter than 50 amino acids were removed. We also used a custom perl script to remove problematic alignment regions using an approach similar to that proposed by Han and colleagues and Ramasamy and colleagues [90, 91]. Rates of molecular 
evolution were determined for Glossina orthologs using PAML 4.7 [92] based on the unrooted tree estimated in our phylogenetic analysis [30] (see below), which has topology (((G. m. morsitans, G. pallidipes), G. austeni), (G. fuscipes, G. palpalis), G. brevipalpis). The rate of nonsynonymous substitution, $d_{\mathrm{N}}$ (leading to amino acid changes), and synonymous substitution, $d_{\mathrm{S}}$ (which should accumulate neutrally), were estimated over all branches of the phylogenetic tree using the "free-ratio" model (M0 [93]; model $=1$ and NSsites $=0)$. This model allows $\omega=d_{\mathrm{N}} / d_{S}$, i.e., the level of selective pressure experienced by a gene, to vary among branches of the tree.

We then used PAML to test different models of substitution rates across coding sites [94, 95], with the aim of detecting genes that either evolved at a different rate or that underwent positive selection along one of the Glossina lineages. To maximize statistical power, these tests were performed only on orthologous sets containing at least five species. In the first test, we compared models that assumed one or more substitution rates across the phylogeny. The first of such models is the basic "one-ratio" branch model (M0), which assumes a constant $\omega$ across the phylogeny (model $=0$ and NSsites $=0$ ). Following the manual recommendations, this model was used to obtain the branch lengths for each gene tree, which were then copied into the tree structure file to be used with the branch and site substitution models. The likelihood of the M0 model was compared to that of a branch model that assumed two $\omega$ values. In the branch model, one $\omega$ value represents the Glossina species with the exception of G. brevipalpis (the so-called foreground branch), and one $\omega$ value for the rest of the tree (the background branches; model $=2$ and NSsites =0). Glossina brevipalpis is not included with the rest of the Glossina species as using an unrooted tree we cannot separate the processes that acted along its lineage from those that took place in the lineage subtending the clade containing the other five species. Subsequently, the value of twice the difference between the two likelihoods was tested using a $\chi^{2}$ test with 1 degree of freedom. The occurrence of positive selection was tested by the branch-site test. In this test (branch-site model A, test 2 [96]), $\omega$ can vary both among sites in the protein and across branches on the tree (model $=2$, NSsites $=2$ ). As for the branch model, we used tree structures with branch lengths estimated by model M0. The null model fixed $\omega_{2}=1$ (fix_omega $=1$, omega $=1$ ), whereas the positive selection model allowed $\omega_{2}>1$ (fix_omega $=0$, omega $=1$ ). The likelihood ratio test had 1 degree of freedom. The occurrence of positive selection was also tested by comparing (nearly) neutral models to models that allow for the occurrence of positive selection (site tests). In a first approach, we compared the likelihood of a model (M1a; model $=0$ and NSsites $=1$ ) that assumes two sets of sites with neutral $(\omega=1)$ or nearly neutral evolution $(0<\omega<1)$, to a model with an additional class of sites with $\omega>1$ (M2a; model $=0$ and NSsites $=2$ ). In a second more realistic approach, we compared the likelihood of a model where ten site classes have $\omega$ values drawn from a $\beta$ distribution (M7; model $=0$ and NSsites $=7$ ) to a model that incorporates an additional class of sites under positive selection (M8; model $=0$ and NSsites $=8$ ). In these cases, each comparison was tested using a $\chi^{2}$ test with 2 degrees of freedom. To account for multiple testing, we also estimated the false discovery rate (FDR) of each test using the $q$-value approach [97] implemented in $R$ [98]. Genes were defined as being under significant positive selection if they had an associated $q$-value < 0.20 . We note that these analyses are conservative regarding the frequency of positive selection, since the reciprocal-best-hit approach is prone to miss genes with high sequence divergence, including those that underwent particularly intense divergent adaptive evolution.

The intersections among the MAGGs and TSTGs found to be under selection in the different Glossina lineages were visualized by a Venn diagram (http:// bioinformatics.psb.ugent.be/webtools/Venn/).

\section{Functional classification of Glossina male reproductive sequences}

Functional classification of tsetse orthologs was performed using $\operatorname{Argot}^{2}$ [99] and the Blast2GO software v.2.8 (https://www.blast2go.com/b2ghome). The CDS of G. m. morsitans reproductive genes were used to perform BLASTx against the NCBI non-redundant (nr) database $\left(e\right.$-value $\left.<10^{-10}\right)$. For Gene Ontology mapping (GO; http://www.geneontology.org) we used Blast2GO to extract GO terms associated with homologies identified by NCBI's BLAST. We retained annotations with $e$-value $<10^{-10}$. We then performed InterPro and InterProScan [100] searches remotely from Blast2GO via the InterPro EBI web server and merged InterProScan GOs with the original GO annotations. The notched box plot figures showing the $d_{\mathrm{N}} / d_{\mathrm{S}}$ relative to each GO functional class (Molecular Function Level III) were developed using R Studio [101]. In the case of novel tsetse proteins (NTP), i.e., sequences sharing no similarity to sequences present in the GenBank database [29] and for which GO terms could not be assigned, but displaying high $d_{N} /$ $d_{S}$ values, potential functional roles have been inferred, when possible, using the InterPro results. 


\section{Supplementary Information}

The online version contains supplementary material available at https://doi. org/10.1186/s12915-021-01148-4.

Additional file 1: Table S1. Level of selective pressure across the 8088 genes with orthologs in at least five Glossina species. Selective pressure $\left(d_{N} / d_{S}\right)$ values were estimated as fixed in the whole phylogeny. Genes over-expressed in MAGs or testes are indicated.

Additional file 2: Table S2. Level of selective pressure across the 5513 genes with orthologs in all six Glossina species. Selective pressure $\left(d_{N} / d_{S}\right)$ values were estimated for each branch of the phylogeny. Genes overexpressed in MAGs or testes are indicated.

Additional file 3: Table S3. List of TSTGS and MAGGS and their distribution among Gene Ontology functional categories. The presence of their protein products in G. m. morsitans spermatophore are reported. Omegafix values are indicated for each gene.

Additional file 4: Table S4. Testes genes $(n=176)$ in G. m. morsitans, G. austeni, G. fuscipes, G. pallidipes and G. palpalis tested for positive selection after site (A and $\mathrm{B})$, branch $(\mathrm{Br})$ and branch-site $(\mathrm{BrS})$ models. Dataset column indicates the number of species in which ortholog sequences of each G. m. morsitans gene were identified (aus $=G$. austeni; b $=G$. brevipalpis; $f=G$. fuscipes; pai $=G$. pallidipes; $p p i=G$. palpalis). Gene ID column reports G. m. morsitans orthologs. NTP indicate genes encoding Novel Tsetse Proteins. * FDR $<0.20$; ${ }^{*}$ FDR $<0.05$; ${ }^{* *}$ FDR $<0.005$.

Additional file 5: Table S5. Number of MAG genes $(n=10)$ in $G$. $m$. morsitans, G. austeni, G. fuscipes, G. pallidipes and G. palpalis tested for positive selection after site (A and $\mathrm{B})$, branch (Br) and branch-site (BrS) models. Dataset column indicates the number of species in which ortholog sequences of each G. m. morsitans gene were identified ( $b=G$. brevipalpis; ppi $=G$. palpalis). Gene ID column reports G. $m$. morsitans orthologs. NTP indicate genes encoding Novel Tsetse Proteins. ${ }^{*}$ FDR $<$ 0.20 ; * FDR $<0.05$; *** FDR $<0.005$.

Additional file 6: Table S6. List of species, strains and genome resources used in this study.

\section{Acknowledgements}

Not applicable.

\section{Authors' contributions}

ARM, GG, AMMA, GMA, and SA conceptualized and supervised this project. GS, FS, LO, OR-S, LMG, and GMA designed and performed experiments; GS, FS, LO, OR-S, DC, and GMA analyzed the data; GS, FS, LO, and OR-S prepared the figures; ARM, FS, LO, and GMA wrote the manuscript with feedback from all authors. All authors read and approved the final manuscript.

\section{Funding}

This work received support from grants NIH R21 Al109263-01 "Expanding the toolbox for tsetse reproductive biology" and NIH R21 Al128523 "Unraveling Intersexual Interactions in Tsetse" (S.A., G.M.A., A.R.M.). This research was conducted in the framework of the Joint Division of FAO/IAEA Co-ordinated Research Project on "Enhancing Vector Refractoriness to Trypanosome Infection" (2013-2018, D42015)(A.R.M., S.A.), and the Joint Division of FAO/ IAEA Co-ordinated Research Project on "Improvement of colony management in insect mass-rearing for SIT applications" (2018-, D42017)(A.M.M.A. S.A.), and the Italian Ministry of Education, University and Research (MIUR): Dipartimenti di Eccellenza Program (2018-2022) - Dept. of Biology and Biotechnology "L. Spallanzani," University of Pavia.

\section{Availability of data and materials}

The data that support the findings of this study are available in the supplementary material of this article. The pipeline used for the identification of the orthologous gene set and the dataset used in PhyloBayes are available in the Open Science Framework data repository at https://osf.io/ zjbdx/?view_only=1b0935ab0e5a447ab3b68dad1aa5a3bd [102].

\section{Declarations}

Ethics approval and consent to participate

Not applicable.

\section{Consent for publication}

Not applicable.

\section{Competing interests}

The authors declare that they have no competing interests.

\section{Author details}

${ }^{1}$ Department of Biology and Biotechnology, University of Pavia, Pavia, Italy. ${ }^{2}$ Institute of Molecular Genetics IGM-CNR "Luigi Luca Cavalli-Sforza", Pavia, Italy. ${ }^{3}$ Research and Innovation Centre, Fondazione Edmund Mach (FEM), San Michele all'Adige, Italy. ${ }^{4}$ Center Agriculture Food Environment (C3A), University of Trento, Trento, Italy. ${ }^{5}$ Insect Pest Control Laboratory, Joint FAO/ IAEA Programme of Nuclear Techniques in Food \& Agriculture, Vienna, Vienna, Austria. ${ }^{6}$ Department of Epidemiology of Microbial Diseases, Yale School of Public Health, New Haven, CT, USA. ${ }^{7}$ Department of Entomology and Nematology, University of California, Davis, Davis, CA, USA.

Received: 28 April 2021 Accepted: 6 September 2021

Published online: 23 September 2021

\section{References}

1. Anholt RRH, O'Grady P, Wolfner MF, Harbison ST. Evolution of reproductive behavior. Genetics. 2020;214(1):49-73. https://doi.org/10.1534/genetics.119.3 02263.

2. Fiumera AC, Dumont BL, Clark AG. Sperm competitive ability in Drosophila melanogaster associated with variation in male reproductive proteins. Genetics. 2005;169(1):243-57. https://doi.org/10.1534/genetics.104.032870.

3. Zhang $\mathrm{R}$, Clark AG, Fiumera AC. Natural genetic variation in male reproductive genes contributes to nontransitivity of sperm competitive ability in Drosophila melanogaster. Mol Ecol. 2013;22(5):1400-15. https://doi. org/10.1111/mec.12113.

4. Swanson WJ, Vacquier VD. The rapid evolution of reproductive proteins. Nat Rev Genet. 2002;3(2):137-44. https://doi.org/10.1038/nrg733.

5. Clark NL, Aagaard JE, Swanson WJ. Evolution of reproductive proteins from animals and plants. Reproduction. 2006;131(1):11-22. https://doi.org/10.153 0/rep.1.00357.

6. Whittle CA, Kulkarni A, Chung N, Extavour CG. Adaptation of codon and amino acid use for translational functions in highly expressed cricket genes. BMC Genomics. 2021;22(1). doi:https://doi.org/10.1186/s12864-021-07411-w

7. Izquierdo A, Fahrenberger M, Persampieri T, Benedict MQ, Giles T, Catteruccia $\mathrm{F}$, et al. Evolution of gene expression levels in the male reproductive organs of Anopheles mosquitoes. Life Sci Alliance. 2019;2(1): e201800191. doi:https://doi.org/10.26508/lsa.201800191

8. Ramm SA, Oliver PL, Ponting CP, Stockley P, Emes RD. Sexual selection and the adaptive evolution of mammalian ejaculate proteins. Mol Biol Evol. 2008:25(1):207-19. https://doi.org/10.1093/molbev/msm242.

9. Karr TL. Fruit flies and the sperm proteome. Hum Mol Genet. 2007;16(R2). doi:https://doi.org/10.1093/hmg/ddm252

10. Bonilla $E, X u E Y$. Identification and characterization of novel mammalian spermatogenic genes conserved from fly to human. Mol Hum Reprod. 2008 14(3):137-42. https://doi.org/10.1093/molehr/gan002.

11. Ravi Ram K, Wolfner MF. Sustained post-mating response in Drosophila melanogaster requires multiple seminal fluid proteins. PLoS Genet. 2007; 3(12):2428-38. https://doi.org/10.1371/journal.pgen.0030238.

12. Haerty W, Jagadeeshan S, Kulathinal RJ, Wong A, Ram KR, Sirot LK, et al. Evolution in the fast lane: rapidly evolving sex-related genes in Drosophila. Genetics. 2007;177(3):1321-35. https://doi.org/10.1534/genetics.107.078865.

13. Begun DJ, Lindfors HA. Rapid evolution of genomic Acp complement in the melanogaster subgroup of Drosophila. Mol Biol Evol. 2005;22(10):2010-21. https://doi.org/10.1093/molbev/msi201.

14. Swanson WJ, Clark AG, Waldrip-Dail HM, Wolfner MF, Aquadro CF. Evolutionary EST analysis identifies rapidly evolving male reproductive proteins in Drosophila. Proc Natl Acad Sci U S A. 2001;98(13):7375-9. https:// doi.org/10.1073/pnas.131568198. 
15. Ahmed-Braimah $Y H$, Unckless RL, Clark AG. Evolutionary dynamics of male reproductive genes in the Drosophila virilis subgroup. G3 (Bethesda). 2017; 7(9):3145-55. doi:https://doi.org/10.1534/g3.117.1136

16. Sepil I, Hopkins BR, Dean R, Thézénas M-L, Charles PD, Konietzny R, et al. Quantitative proteomics identification of seminal fluid proteins in male Drosophila melanogaster. Mol Cell Proteomics. 2019;18(Suppl 1):S46-58. https://doi.org/10.1074/mcp.RA118.000831.

17. Andrés JA, Maroja LS, Bogdanowicz SM, Swanson WJ, Harrison RG. Molecular evolution of seminal proteins in field crickets. Mol Biol Evol. 2006; 23(8):1574-84. https://doi.org/10.1093/molbev/msl020.

18. Andrés JA, Larson EL, Bogdanowicz SM, Harrison RG. Patterns of transcriptome divergence in the male accessory gland of two closely related species of field crickets. Genetics. 2013;193(2):501-13. https://doi. org/10.1534/genetics.112.142299.

19. Braswell WE, Andrés JA, Maroja LS, Harrison RG, Howard DJ, Swanson WJ. Identification and comparative analysis of accessory gland proteins in Orthoptera. Genome. 2006;49(9):1069-80. https://doi.org/10.1139/g06-061.

20. Patlar B, Civetta A. Speciation and changes in male gene expression in Drosophila. Genome. 2021;64(2):63-73. https://doi.org/10.1139/gen-2 020-0025.

21. Singh RS. Patterns of species divergence and genetic theories of speciation. In: Wöhrmann K, Jain SK, editors. Population Biology. Berlin, Heidelberg: Springer; 1990. p. 231-65. https://doi.org/10.1007/978-3-642-74474-7_8.

22. Singh RS. Toward a unified theory of speciation. In: Singh RS, Krimbas C, editors. Evolutionary genetics: from molecules to morphology. London: Cambridge University Press; 2000. p. 570-604.

23. Wu C, Davis AW. Evolution of postmating reproductive isolation: the composite nature of Haldane's rule and its genetic bases. Am Nat. 1993; 142(2):187-212. https://doi.org/10.1086/285534.

24. Benoit JB, Attardo GM, Baumann AA, Michalkova V, Aksoy S. Adenotrophic viviparity in tsetse flies: potential for population control and as an insect model for lactation. Annu Rev Entomol. 2015;60(1):351-71. https://doi.org/1 0.1146/annurev-ento-010814-020834.

25. Briceño RD, Wegrzynek D, Chinea-Cano E, Eberhard WG, dos Santos Rolo T. Movements and morphology under sexual selection: tsetse fly genitalia. Ethol Ecol Evol. 2010;22(4):385-91. https://doi.org/10.1080/03949370.2010. 505581

26. Shaw WR, Attardo GM, Aksoy S, Catteruccia F. A comparative analysis of reproductive biology of insect vectors of human disease. Curr Opin Insect Sci. 2015;10:142-8. https://doi.org/10.1016/j.cois.2015.05.001.

27. Attardo GM, Tam N, Parkinson D, Mack LK, Zahnle XJ, Arguellez J, et al. Interpreting morphological adaptations associated with viviparity in the tsetse fly Glossina morsitans (Westwood) by three-dimensional analysis. Insects. 2020;11(10):651. https://doi.org/10.3390/insects11100651.

28. Odhiambo TR, Kokwaro ED, Sequeira LM. Histochemical and ultrastructural studies of the male accessory reproductive glands and spermatophore of the tsetse, Glossina morsitans morsitans Westwood. Int J Trop Insect Sci. 1983;4(03):227-36. https://doi.org/10.1017/S1742758400001193.

29. Scolari F, Benoit JB, Michalkova V, Aksoy E, Takac P, Abd-Alla AMM, et al. The spermatophore in Glossina morsitans morsitans: insights into male contributions to reproduction. Sci Rep. 2016;6(1):20334. https://doi.org/10.1 038/srep20334.

30. Attardo GM, Abd-Alla AMM, Acosta-Serrano A, Allen JE, Bateta R, Benoit JB, et al. Comparative genomic analysis of six Glossina genomes, vectors of African trypanosomes. Genome Biol. 2019;20(1):187. https://doi.org/10.1186/ s13059-019-1768-2.

31. Clausen PH, Adeyemi I, Bauer B, Breloeer M, Salchow F, Staak C. Host preferences of tsetse (Diptera: Glossinidae) based on bloodmeal identifications. Med Vet Entomol. 1998;12(2):169-80. https://doi.org/10.1046/ j.1365-2915.1998.00097.x

32. Barrett MP. The rise and fall of sleeping sickness. Lancet. 2006;367(9520): 1377-8. https://doi.org/10.1016/S0140-6736(06)68591-7.

33. Krafsur E. Tsetse flies: Genetics, evolution, and role as vectors. Infect Genet Evol. 2009;9(1):124-41. https://doi.org/10.1016/j.meegid.2008.09.010.

34. Torr SJ, Vale GA. Know your foe: lessons from the analysis of tsetse fly behaviour. Trends Parasitol. 2015;31(3):95-9. https://doi.org/10.1016/j.pt.2 014.12.010.

35. Sirot LK, LaFlamme BA, Sitnik JL, Rubinstein CD, Avila FW, Chow CY, et al. Molecular social interactions: Drosophila melanogaster seminal fluid proteins as a case study. Adv Genet. 2009;68:23-56. https://doi.org/10.1016/S0065-2 660(09)68002-0.
36. Bonomi A, Bassetti F, Gabrieli P, Beadell J, Falchetto M, Scolari F, et al. Polyandry is a common event in wild populations of the tsetse fly Glossina fuscipes fuscipes and may impact population reduction measures. PLoS Negl Trop Dis. 2011;5(6):e1190. https://doi.org/10.1371/journal.pntd.0001190.

37. Rogers A. A method for gauging the frequency of multiple mating of female Glossina pallidipes in the field. Trans R Soc Trop Med Hyg. 1973;67(2): 299. https://doi.org/10.1016/0035-9203(73)90228-9.

38. Gooding RH. Tsetse genetics: a review. Quaest Entomol. 1984;20:89-128.

39. International Glossina Genome Initiative. Genome sequence of the tsetse fly (Glossina morsitans): vector of African trypanosomiasis. Science. 2014; 344(6182):380-6. https://doi.org/10.1126/science.1249656.

40. Bayram H, Sayadi A, Goenaga J, Immonen E, Arnqvist G. Novel seminal fluid proteins in the seed beetle Callosobruchus maculatus identified by a proteomic and transcriptomic approach. Insect Mol Biol. 2017;26(1):58-73. https://doi.org/10.1111/imb.12271.

41. Bayram H, Sayadi A, Immonen $\mathrm{E}$, Arnqvist G. Identification of novel ejaculate proteins in a seed beetle and division of labour across male accessory reproductive glands. Insect Biochem Mol Biol. 2019;104:50-7. https://doi. org/10.1016/j.ibmb.2018.12.002.

42. Findlay GD, Yi X, MacCoss MJ, Swanson WJ. Proteomics reveals novel Drosophila seminal fluid proteins transferred at mating. PLoS Biol. 2008;6(7): e178. https://doi.org/10.1371/journal.pbio.0060178.

43. Karr TL, Southern H, Rosenow MA, Gossmann TI, Snook RR. The old and the new: discovery proteomics identifies putative novel seminal fluid proteins in Drosophila. Mol Cell Proteomics. 2019;18(Suppl 1):S23-33. https://doi.org/1 0.1074/mcp.RA118.001098.

44. Kramerova IA, Kawaguchi N, Fessler LI, Nelson RE, Chen Y, Kramerov AA, et al. Papilin in development; a pericellular protein with a homology to the ADAMTS metalloproteinases. Development. 2000;127(24):5475-85. https:// doi.org/10.1242/dev.127.24.5475.

45. Zeh JA, Zeh DW. Viviparity-driven conflict. Ann N Y Acad Sci. 2008;1133(1): 126-48. https://doi.org/10.1196/annals.1438.006.

46. Dapper AL, Wade MJ. Relaxed selection and the rapid evolution of reproductive genes. Trends Genet. 2020;36(9):640-9. https://doi.org/10.1016/ j.tig.2020.06.014

47. Zeh DW, Zeh JA. Reproductive mode and speciation: the viviparity-driven conflict hypothesis. BioEssays. 2000;22(10):938-46. doi:10.1002/15211878(200010)22:10 < 938::AID-BIES9 > 3.0.CO;2-9

48. Briceño RD, Eberhard WG. Experimental demonstration of possible cryptic female choice on male tsetse fly genitalia. J Insect Physiol. 2009;55(11):989_ 96. https://doi.org/10.1016/j.jinsphys.2009.07.001.

49. Eberhard WG, Lehmann GUC. Demonstrating sexual selection by cryptic female choice on male genitalia: what is enough? Evolution (N Y). 2019; 73(12):2415-35. https://doi.org/10.1111/evo.13863.

50. Arnqvist G, Rowe L. Sexual Conflict. Princeton University Press: Princeton; 2005. https://doi.org/10.1515/9781400850600.

51. Sirot LK, Wong A, Chapman T, Wolfner MF. Sexual conflict and seminal fluid proteins: a dynamic landscape of sexual interactions. Cold Spring Harb Perspect Biol. 2015;7(2):a017533. https://doi.org/10.1101/ cshperspect.a017533.

52. Sirot LK, Wolfner MF. Who's zooming who? Seminal fluids and cryptic female choice in Diptera. In: Peretti A, Aisenberg A, editors. Cryptic Female Choice in Arthropods. Cham: Springer; 2015. p. 351-84. https://doi.org/10.1 007/978-3-319-17894-3_13

53. Ravi Ram K, Wolfner MF. Seminal influences: Drosophila Acps and the molecular interplay between males and females during reproduction. Integr Comp Biol. 2007;47(3):427-45. https://doi.org/10.1093/icb/icm046.

54. Chapman T. The soup in my fly: evolution, form and function of seminal fluid proteins. PLoS Biol. 2008;6(7):e179. https://doi.org/10.1371/ journal.pbio.0060179.

55. Sun JS, Xiao S, Carlson JR. The diverse small proteins called odorant-binding proteins. Open Biol. 2018;8(12):180208. https://doi.org/10.1098/rsob.180208.

56. Amenya DA, Chou W, Li J, Yan G, Gershon PD, James AA, et al. Proteomics reveals novel components of the Anopheles gambiae eggshell. J Insect Physiol. 2010;56(10):1414-9. https://doi.org/10.1016/j.jinsphys.2010.04.013.

57. Pelosi P, Zhu J, Knoll W. Odorant-binding proteins as sensing elements for odour monitoring. Sensors. 2018;18(10):3248. https://doi.org/10.3390/s181 03248.

58. Pelosi P, lovinella I, Felicioli A, Dani FR. Soluble proteins of chemical communication: an overview across arthropods. Front Physiol. 2014;5. https://doi.org/10.3389/fphys.2014.00320. 
59. Pelosi P, lovinella I, Zhu J, Wang G, Dani FR. Beyond chemoreception: diverse tasks of soluble olfactory proteins in insects. Biol Rev Camb Philos Soc. 2018;93(1):184-200. https://doi.org/10.1111/brv.12339.

60. Sun $Y-L$, Huang L-Q, Pelosi P, Wang C-Z. Expression in antennae and reproductive organs suggests a dual role of an odorant-binding protein in two sibling Helicoverpa species. PLoS One. 2012;7(1):e30040. https://doi. org/10.1371/journal.pone.0030040.

61. McAfee A, Chapman A, Pettis JS, Foster $\sqcup$, Tarpy DR. Trade-offs between sperm viability and immune protein expression in honey bee queens (Apis mellifera). Commun Biol. 2021;4(1):48. https://doi.org/10.1038/s42003-020-01586-w.

62. Rihani K, Ferveur J-F, Briand L. The 40-year mystery of insect odorantbinding proteins. Biomolecules. 2021;11(4):509. https://doi.org/10.3390/ biom11040509.

63. Hoppenheit A, Murugaiyan J, Bauer B, Steuber S, Clausen P-H, Roesler U. Identification of tsetse (Glossina spp.) using matrix-assisted laser desorption/ ionisation time of flight mass spectrometry. PLoS Negl Trop Dis. 2013;7(7): e2305. doi:https://doi.org/10.1371/journal.pntd.0002305

64. Leak SGA. Tsetse biology and ecology: their role in the epidemiology and control of trypanosomosis. Wallingford: CABI International; 1999.

65. Cockerell TDA. A fossil tsetse-fly in Colorado. Nature. 1907;76(1973):414. https://doi.org/10.1038/076414b0

66. Junqueira ACM, Azeredo-Espin AML, Paulo DF, Marinho MAT, Tomsho LP, Drautz-Moses DI, et al. Large-scale mitogenomics enables insights into Schizophora (Diptera) radiation and population diversity. Sci Rep. 2016;6(1): 21762. https://doi.org/10.1038/srep21762.

67. Cerling TE, Harris JM, Ambrose SH, Leakey MG, Solounias N. Dietary and environmental reconstruction with stable isotope analyses of herbivore tooth enamel from the Miocene locality of Fort Ternan. Kenya. J Hum Evol. 1997;33(6):635-50. https://doi.org/10.1006/jhev.1997.0151.

68. Bursell E. The water balance of tsetse pupae. Philos Trans R Soc Lond B Biol Sci. 1958;241(680):179-210. https://doi.org/10.1098/rstb.1958.0002.

69. Dyer N, Lawton S, Ravel S, Choi K, Lehane M, Robinson A, et al. Molecular phylogenetics of tsetse flies (Diptera: Glossinidae) based on mitochondrial (COI, 16S, ND2) and nuclear ribosomal DNA sequences, with an emphasis on the palpalis group. Mol Phylogenet Evol. 2008;49(1):227-39. https://doi. org/10.1016/j.ympev.2008.07.011.

70. Wall R, Langley PA. The mating behaviour of tsetse flies (Glossina): a review. Physiol Entomol. 1993;18(2):211-8. https://doi.org/10.1111/j.1365-3032.1993. tb00470.x.

71. Richards OW, Glasgow JP. The distribution and abundance of tsetse. J Anim Ecol. 1964;33(3):528. https://doi.org/10.2307/2577.

72. Parrett JM, Knell RJ. The effect of sexual selection on adaptation and extinction under increasing temperatures. Proc R Soc B Biol Sci. 2018; 285(1877):20180303. https://doi.org/10.1098/rspb.2018.0303.

73. Vreysen MJB, Van der Vloedt AMV. The use of gamma irradiated Glossina austeni females as sentinel insects for entomological monitoring in tsetse control programmes. Rev Elev Med Vet Pays Trop. 1992;45:303-9.

74. Ford J. The distribution of the vectors of African pathogenic trypanosomes. Bull World Health Organ. 1963;28(5-6):653-69.

75. Malele II, Parker AG. Mating age of Glossina austeni Newstead. Acta Trop. 1999;72(3):319-24. https://doi.org/10.1016/S0001-706X(98)00098-9.

76. Foster WA. Male sexual maturation of the tsetse flies Glossina morsitans Westwood and G. austeni Newstead (Dipt., Glossinidae) in relation to blood feeding. Bull Entomol Res. 1976;66(3):389-99. https://doi.org/10.1017/S00074 85300006787.

77. Zeh JA, Zeh DW. The evolution of polyandry I: Intragenomic conflict and genetic incompatibility. Proc R Soc B Biol Sci. 1996;263(1377):1711-7. https://doi.org/10.1098/rspb.1996.0250.

78. Zeh JA, Zeh DW. The evolution of polyandry II: Post-copulatory defences against genetic incompatibility. Proc R Soc B Biol Sci. 1997;264(1378):69-75. https://doi.org/10.1098/rspb.1997.0010.

79. Zeh JA, Zeh DW. Reproductive mode and the genetic benefits of polyandry. Anim Behav. 2001;61(6):1051-63. https://doi.org/10.1006/anbe.2000.1705

80. Crespi B, Semeniuk C. Parent-offspring conflict in the evolution of vertebrate reproductive mode. Am Nat. 2004;163(5):635-53. https://doi.org/10.1086/382734.

81. Katoh K. MAFFT: a novel method for rapid multiple sequence alignment based on fast Fourier transform. Nucleic Acids Res. 2002;30(14):3059-66. https://doi.org/10.1093/nar/gkf436.

82. Lartillot N, Lepage T, Blanquart S. PhyloBayes 3: a Bayesian software package for phylogenetic reconstruction and molecular dating. Bioinformatics. 2009; 25(17):2286-8. https://doi.org/10.1093/bioinformatics/btp368.
83. Mcintosh WC, Geissman JW, Chapin CE, Kunk MJ, Henry CD. Calibration of the latest Eocene-Oligocene geomagnetic polarity time scale using 40Ar/ 39Ad dated ignimbrites. Geology. 1992;20(5):459-63. https://doi.org/10.113 0/0091-7613(1992)020<0459:COTLEO>2.3.CO;2.

84. Benton MJ, Donoghue PCJ. Paleontological evidence to date the tree of life. Mol Biol Evol. 2006;24(1):26-53. https://doi.org/10.1093/molbev/msl150.

85. Obbard DJ, Maclennan J, Kim K-W, Rambaut A, O'Grady PM, Jiggins FM. Estimating divergence dates and substitution rates in the Drosophila phylogeny. Mol Biol Evol. 2012;29(11):3459-73. https://doi.org/10.1093/ molbev/mss150.

86. Yang Z, Rannala B. Bayesian estimation of species divergence times under a molecular clock using multiple fossil calibrations with soft bounds. Mol Biol Evol. 2006;23(1):212-26. https://doi.org/10.1093/molbev/msj024.

87. Ward N, Moreno-Hagelsieb G. Quickly finding orthologs as reciprocal best hits with BLAT, LAST, and UBLAST: how much do we miss? PLOS One. 2014 9(7):e101850. https://doi.org/10.1371/journal.pone.0101850.

88. Löytynoja A, Goldman N. A model of evolution and structure for multiple sequence alignment. Philos Trans R Soc B Biol Sci. 2008;363(1512):3913-9. https://doi.org/10.1098/rstb.2008.0170.

89. Abascal F, Zardoya R, Telford MJ. TranslatorX: multiple alignment of nucleotide sequences guided by amino acid translations. Nucleic Acids Res. 2010;38(suppl_2):W7-13. doi:https://doi.org/10.1093/nar/gkq291

90. Han MV, Demuth JP, McGrath CL, Casola C, Hahn MW. Adaptive evolution of young gene duplicates in mammals. Genome Res. 2009;19(5):859-67. https://doi.org/10.1101/gr.085951.108.

91. Ramasamy S, Ometto L, Crava CM, Revadi S, Kaur R, Horner DS, et al. The evolution of olfactory gene families in Drosophila and the genomic basis of chemical-ecological adaptation in Drosophila suzukii. Genome Biol Evol. 2016;8(8):2297-311. https://doi.org/10.1093/gbe/evw160.

92. Yang Z. PAML 4: Phylogenetic analysis by Maximum Likelihood. Mol Biol Evol. 2007;24(8):1586-91. https://doi.org/10.1093/molbev/msm088.

93. Yang Z. Likelihood ratio tests for detecting positive selection and application to primate lysozyme evolution. Mol Biol Evol. 1998;15(5):568-73. https://doi.org/10.1093/oxfordjournals.molbev.a025957.

94. Yang Z, Nielsen R, Goldman N, Pedersen AM. Codon-substitution models for heterogeneous selection pressure at amino acid sites. Genetics. 2000;155(1): 431-49. https://doi.org/10.1093/genetics/155.1.431.

95. Yang Z, Nielsen R. Estimating synonymous and nonsynonymous substitution rates under realistic evolutionary models. Mol Biol Evol. 2000; 17(1):32-43. https://doi.org/10.1093/oxfordjournals.molbev.a026236.

96. Yang Z. Bayes empirical Bayes inference of amino acid sites under positive selection. Mol Biol Evol. 2005;22(4):1107-18. https://doi.org/10.1093/molbev/ msi097.

97. Storey JD. A direct approach to false discovery rates. J Roy Stat Soc B Stat Methodol. 2002;64(3):479-98. https://doi.org/10.1111/1467-9868.00346.

98. R Core Team. R: A language and environment for statistical computing. $R$ Foundation for Statistical Computing, Vienna; http://www.r-project.org/ index.html. 2020. Accessed 24 Aug 2021.

99. Falda M, Toppo S, Pescarolo A, Lavezzo E, Di Camillo B, Facchinetti A, et al. Argot2: a large scale function prediction tool relying on semantic similarity of weighted Gene Ontology terms. BMC Bioinformatics. 2012;13(S4):S14. https://doi.org/10.1186/1471-2105-13-S4-S14.

100. Quevillon E, Silventoinen V, Pillai S, Harte N, Mulder N, Apweiler R, et al. InterProScan: protein domains identifier. Nucleic Acids Res. 2005;33(Web Server issue):W116-20. doi:https://doi.org/10.1093/nar/gki442

101. RStudio Team. RStudio: Integrated development for R. RStudio, PBC, Boston; http://www.rstudio.com/. 2020. Accessed 24 Aug 2021

102. Savini G, Scolari F, Ometto L, Rota-Stabelli O, Carraretto D, Gomulski LM, et al. Viviparity and habitat restrictions may influence the evolution of male reproductive genes in Glossina species. Open Science Framework https:// osf.io/zjbdx/?view_only=1b0935ab0e5a447ab3b68dad1aa5a3bd. 2021.

\section{Publisher's Note}

Springer Nature remains neutral with regard to jurisdictional claims in published maps and institutional affiliations. 